\title{
Effect of sperm preparation method on in vitro fertilization in pigs
}

\author{
C. Matás, P. Coy, R. Romar, M. Marco, J. Gadea and S. Ruiz \\ Department of Physiology (Veterinary Physiology), Faculty of Veterinary Science, University of Murcia, \\ 30071-Murcia, Spain
}

This study was designed to determine the effect of different sperm preparation treatments before IVF on the acrosome reaction, oocyte penetration time, early embryo development and timing of female and male pronucleus formation. Pooled sperm-rich fractions were (i) washed in PBS, (ii) left unwashed, or (iii) layered in a Percoll gradient. In Expt 1, the proportion of acrosome-reacted spermatozoa, determined by staining with fluorescein isothiocyanate-labelled peanut agglutinin lectin and propidium iodide, was highest after treatment with Percoll $(P<0.001)$. In Expt 2, oocytes matured in vitro were co-cultured with spermatozoa for 2,4 or $6 \mathrm{~h}$. Attached spermatozoa were then removed and the oocytes were cultured in fresh IVF medium for $16 \mathrm{~h}$. Both sperm treatment and co-culture time were found to affect penetrability and monospermy rates $(P<0.001)$; spermatozoa treated with Percoll showed fastest oocyte penetration and highest penetrability. In Expt 3, matured oocytes were co-incubated with spermatozoa pretreated by the procedures (i), (ii) and (iii) for 2, 6 and $2 \mathrm{~h}$ respectively. Putative zygotes were then washed and transferred to medium NCSU-23 until the blastocyst stage. In this experiment, sperm treatment had a significant effect on the cleavage rate $(P<0.001)$ and rate of blastocyst formation $(P<0.05)$; the group treated with Percoll showed the highest rate of blastocyst formation. Finally, in Expt 4, timing of female and male pronucleus formation for each sperm treatment was determined 4, 6 and $8 \mathrm{~h}$ after insemination. The time of female and male pronucleus formation was affected by the sperm treatment and was faster for the Percoll group $(P<0.05)$. The findings of the present study indicate that treatment with Percoll yields the best results in this in vitro pig embryo production system.

\section{Introduction}

Despite recent developments in the in vitro maturation (IVM) and in vitro fertilization (IVF) of pig oocytes, the production of pig embryos in vitro is still relatively inefficient compared with results obtained with oocytes matured and fertilized in vivo (for review, see Abeydeera, 2002). The main reasons for this limited performance are polyspermy after IVF and the poor developmental ability of embryos produced by IVM-IVF (Kikuchi et al., 2002). Although the quality of pig oocytes matured in vitro has improved over the last few years (Funahashi and Day, 1993; Funahashi et al., 1997; Abeydeera et al., 1998a,b), pig IVF still remains to be standardized as results emerging from different laboratories are highly variable. Semen quality has been suggested as a main source of variation (Harrison, 1997), yet few studies have compared the effects on the final outcome of subjecting spermatozoa from the same boar to different treatments

Email: cmatas@um.es
(Long et al., 1999; Matás et al., 2000). Moreover, the unpredictability of the acrosome reaction in vitro in boar spermatozoa and an often inadequate sperm motility pattern in the IVF system have both been identified as factors that contribute significantly to this variability of in vitro systems (Grant et al., 1994; Coy et al., 2002).

Hyperactivation and the acrosome reaction occur after capacitation and are crucial for successful fertilization (Yanagimachi, 1994). Thus, when culture conditions do not produce efficient capacitation, the relatively high concentration of spermatozoa needed for insemination is thought to be a major factor contributing to the high incidence of polyspermic penetrations, leading to a low rate of blastocyst formation (Funahashi and Day, 1997).

Mature mammalian spermatozoa are combined in vivo, with seminal plasma, a milieu of secretions derived from the accessory glands (Mann, 1964). However, upon entry of spermatozoa into the female reproductive tract, seminal plasma is removed so that spermatozoa can be rendered capable of fertilizing oocytes. Several mechanisms, including sperm capacitation and the acrosome reaction for IVF and sex selection, require that 
spermatozoa are removed from the seminal plasma in vitro. Several procedures have been designed to remove diluent media, cryoprotectants or decapacitating factors from the seminal plasma. Among these methods are swim-up (Berger et al., 1985; Parrish and Foote, 1987), the Percoll discontinuous gradient (Grant et al.,1994; Jeong and Yang, 2001), Sephadex gel filtration (Steeno et al., 1985), glass wool filtration (Pereira et al., 2000), glass bead columns (Daya et al., 1987) and albumin gradients (Han et al., 1999; Iwasaki et al., 1999; Sun et al., 2001). However, some research teams prefer not to treat spermatozoa before IVF, but concentrate them by centrifugation before dilution in the fertilization medium (Martinez et al., 1996; Gadea and Matas, 2000). Given the current lack of data, information on the effects of these treatments on IVF and embryo development would help understanding of how these methods of processing boar sperm can affect the outcome of IVF.

Assessing the acrosome reaction provides information on the stage of spermatozoa added to the IVF system, and may provide insight into the reasons for polyspermic penetrations (Coy et al., 2002). The presence of a large number of spermatozoa at the early stage of the spontaneous acrosome reaction in the coculture (Funahashi and Nagai, 2001) gives rise to high polyspermy rates, and fresh boar spermatozoa may be able to penetrate oocytes for up to $23 \mathrm{~h}$ of coculture (Martinez et al., 1996), which also enhances polyspermy. Therefore, it would be desirable to explore the effects of gamete co-incubation time on outcome and establish whether sperm processing before IVF affects the timing of subsequent events such as pronuclei formation.

Under optimal conditions of pig embryo production in vitro, a high percentage of oocytes fail to reach the blastocyst stage (Abeydeera, 2002). There is a clear relationship between time of first cleavage in vitro and developmental ability in cattle (Lonergan et al., 1999); the earliest-cleaving oocytes are more likely to develop to the blastocyst stage than those cleaving later. Jaakma et al. (1997) indicated that embryonic development up to blastocyst formation in cattle varies depending on the procedures used for the preparation and fertilization of bull spermatozoa. Asynchronous development of the two pronuclei could contribute to poor cleavage rates and has been attributed to deficient oocyte maturation (for review, see Nagai, 1994), although it could be caused by a delay in capacitation and the acrosome reaction, reducing cleavage but not fertilization rates.

The aim of the present study was to evaluate the effects of three methods of processing pig spermatozoa before IVF on: (a) percentage of acrosome-reacted spermatozoa; (b) IVF parameters, including percentages of penetration and monospermy; (c) embryo development parameters, including percentages of cleavage or blastocysts; and (d) the timing of pronuclei formation.

\section{Materials and Methods}

Unless otherwise indicated, all the chemicals used in this study were purchased from Sigma-Aldrich Química SA (Madrid).

\section{Sperm preparation}

Semen was collected once or twice per week from three stud and fertility tested boars by the gloved-hand method. The sperm-rich fraction was collected, diluted in Beltsville thawing solution (BTS) and immediately transported to the laboratory. Variation among individual treatments was eliminated by mixing equal semen samples from the three boars. The semen samples were then: (i) washed in Dulbecco's phosphate-buffered saline (DPBS) supplemented with $0.1 \%$ BSA, (ii) left unwashed, or (iii) washed on a Percoll ${ }^{\circledR}$ (Pharmacia, Uppsala) gradient.

Washing with PBS was performed by centrifuging a $10 \mathrm{ml}$ aliquot of the semen mixture three times at $900 \mathrm{~g}$ for $10 \mathrm{~min}$ in DPBS supplemented with $0.1 \%$ BSA (fraction V, A-9647). At the end of the washing procedure, the pellet was resuspended at a concentration of $10^{5}$ cells $\mathrm{ml}^{-1}$ in Tyrode's albumin lactate pyruvate (TALP) medium (Rath et al., 1999) pre-equilibrated overnight at $38.5^{\circ} \mathrm{C}$ in $5 \% \mathrm{CO}_{2}$ in $100 \%$ humidified air.

In the unwashed group, the semen samples were centrifuged at $1200 \mathrm{~g}$ for $3 \mathrm{~min}$ and the resultant sperm pellets were diluted to $10^{5}$ cells $\mathrm{ml}^{-1}$ in TALP medium.

Percoll treatment involved layering a $0.5 \mathrm{ml}$ aliquot of semen on a discontinuous 45 and $90 \%(\mathrm{v} / \mathrm{v})$ Percoll gradient (Parrish et al., 1995) and centrifuging at $700 \mathrm{~g}$ for $30 \mathrm{~min}$. Cells collected from the bottom of the $90 \%$ fraction were washed in TALP medium by centrifugation at $100 \mathrm{~g}$ for $10 \mathrm{~min}$. The sperm pellet was resuspended to give a final concentration of $10^{5}$ cells $\mathrm{ml}^{-1}$.

\section{Acrosome reaction pattern}

Pretreated sperm samples were incubated in TALP medium at $38.5^{\circ} \mathrm{C}$ under $5 \% \mathrm{CO}_{2}$ in $100 \%$ humidified air. Every $30 \mathrm{~min}$ (from 0 to $150 \mathrm{~min}$ ), a $100 \mu \mathrm{l}$ aliquot of the sperm suspension from each treatment group was supplemented with $5 \mu \mathrm{l}$ fluorescein isothiocyanatelabelled peanut agglutinin (FITC-PNA) $(200 \mu \mathrm{g}$ FITCPNA $\mathrm{ml}^{-1}$ ) and $5 \mu \mathrm{l}$ of propidium iodide (PI) $(200 \mu \mathrm{g}$ $\left.\mathrm{PI} \mathrm{m}{ }^{-1}\right)$, kept at $38^{\circ} \mathrm{C}$ for $5 \mathrm{~min}$ and finally fixed in $10 \mu \mathrm{l}$ paraformaldehyde (1\% (v/v) in saline solution). Spermatozoa were then examined under an epifluorescence microscope and divided into three categories according to their FITC-PNA-PI staining pattern (Coy et al., 2002): (i) spermatozoa with no FITCPNA or PI staining were considered to be live and acrosome intact; (ii) spermatozoa with no PI staining but with acrosomal areas stained with FITC-PNA were considered to be live and acrosome reacted, and (iii) spermatozoa stained with $\mathrm{PI}$ were considered to have 
damaged membranes (irrespective of degree of FITCPNA staining).

\section{Oocyte collection and in vitro maturation}

Within 30 min of slaughter, ovaries from prepubertal gilts were transported to the laboratory in saline $(0.9 \%$ $(\mathrm{w} / \mathrm{v}) \mathrm{NaCl})$ containing $100 \mu \mathrm{g}$ kanamycin sulphate $\mathrm{ml}^{-1}$ at $37^{\circ} \mathrm{C}$, and then washed once in $0.04 \%(\mathrm{w} / \mathrm{v})$ cetrimide solution and twice in saline. Oocyte-cumulus cell complexes were collected from non-atretic follicles (3-6 $\mathrm{mm}$ diameter), washed twice in $35 \mathrm{~mm}$ plastic Petri dishes containing DPBS supplemented with $4 \mathrm{mg}$ polyvinyl alcohol (PVA) $\mathrm{ml}^{-1}$, and twice more in maturation medium previously equilibrated for at least $3 \mathrm{~h}$ at $38.5^{\circ} \mathrm{C}$ under $5 \% \mathrm{CO}_{2}$ in $100 \%$ humidified air. Only oocytes harvested within $2 \mathrm{~h}$ of slaughter (Matás et al., 1996) with a homogeneous cytoplasm and a complete, dense cumulus oophorus were matured. The medium used for oocyte maturation was North Carolina State University 37 (NCSU-37; Petters and Wells, 1993) supplemented with $0.57 \mathrm{mmol}$ cysteine $\mathrm{I}^{-1}, 1 \mathrm{mmol}$ dibutyryl cAMP $\mathrm{I}^{-1}, 5 \mu \mathrm{g}$ insulin $\mathrm{ml}^{-1}$, $50 \mu \mathrm{mol} \beta$-mercaptoethanol $\mathrm{I}^{-1}, 10$ iu equine chorionic gonadotrophin $\mathrm{ml}^{-1}$ (Foligon, Intervet International BV, Boxmeer), 10 iu human chorionic gonadotrophin $\mathrm{ml}^{-1}$ (Chorulon, Intervet International BV, Boxmeer), and 10\% $(\mathrm{v} / \mathrm{v})$ pig follicular fluid.

Groups of 50 oocytes were cultured in $500 \mu \mathrm{l}$ maturation medium for $20-22 \mathrm{~h}$ at $38.5^{\circ} \mathrm{C}$ under $5 \%$ $\mathrm{CO}_{2}$ in air. Once cultured, the oocytes were washed twice, transferred to fresh maturation medium with no hormone supplements or dibutyryl cAMP, and cultured for a further 20-22 h (Funahashi and Day, 1993).

\section{In vitro fertilization}

The basic medium used for IVF was essentially the same as that used by Rath et al. (1999) and is referred to as TALP medium: $114.06 \mathrm{mmol} \mathrm{NaCl} \mathrm{I}^{-1}$, $3.2 \mathrm{mmol} \mathrm{KCl} \mathrm{I}{ }^{-1}, 8 \mathrm{mmol}$ calcium lactate $\cdot 5 \mathrm{H}_{2} \mathrm{O} \mathrm{I}^{-1}$, $0.5 \mathrm{mmol} \mathrm{MgCl}_{2} \cdot 6 \mathrm{H}_{2} \mathrm{O} \mathrm{I}^{-1}, 0.35 \mathrm{mmol} \mathrm{NaH}_{2} \mathrm{PO}_{4}$

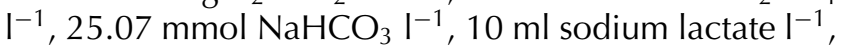
$1.1 \mathrm{mmol}$ Na pyruvate $\mathrm{I}^{-1}, 5 \mathrm{mmol}$ glucose $\mathrm{I}^{-1}, 2 \mathrm{mmol}$ caffeine $\mathrm{I}^{-1}, 3 \mathrm{mg} \mathrm{BSA} \mathrm{ml}^{-1}$ (fraction $\mathrm{V}, \mathrm{A}-9647$ ), $1 \mathrm{mg}$ PVA $\mathrm{ml}^{-1}$ and $0.17 \mathrm{mmol}$ kanamycin sulphate $\mathrm{I}^{-1}$.

Oocytes cultured for $44 \mathrm{~h}$ in maturation medium were mechanically stripped of cumulus by gentle aspiration with a pipette. Denuded oocytes were washed three times in TALP medium and groups of 30-35 oocytes transferred to each well of four-well Nunc multidishes (Nunc, Roskilde) containing $250 \mu \mathrm{l} \mathrm{TALP}$ medium, and equilibrated overnight at $38.5^{\circ} \mathrm{C}$ under $5 \% \mathrm{CO}_{2}$. Sperm suspensions $(250 \mu \mathrm{l})$ from each treatment group were added to each fertilization well to obtain a final concentration of $5 \times 10^{4}$ cells $\mathrm{ml}^{-1}$.
Sixteen hours (Expt 2) or 4, 6 and $8 \mathrm{~h}$ (Expt 4) after insemination, oocytes were fixed, stained with $1 \%(\mathrm{w} / \mathrm{v})$ lacmoid and examined at $\times 400$ magnification under a phase-contrast microscope. The variables analysed were sperm penetration, mean number of spermatozoa per oocyte, rate of monospermy and pronuclear formation.

\section{Embryo culture}

The embryo culture medium was NCSU-23, containing $0.4 \%(\mathrm{w} / \mathrm{v}) \mathrm{BSA}, 75 \mu \mathrm{g}$ potassium penicillin $\mathrm{G} \mathrm{ml}^{-1}$ and $50 \mu \mathrm{g}$ streptomycin sulphate $\mathrm{ml}^{-1}$ (Macháty et al., 1998). After sperm-oocyte co-incubation, putative zygotes were washed three times in NCSU-23 previously equilibrated overnight, transferred in groups of 40-50 to a four-well Nunc multidish containing $500 \mu \mathrm{I}$ NCSU23 per well, and incubated at $38.5^{\circ} \mathrm{C}$ and $5 \% \mathrm{CO}_{2}$ in $100 \%$ humidified air. At 48 and $144 \mathrm{~h}$ after fertilization, cleavage rate and blastocyst formation, respectively, were evaluated under a stereomicroscope. Blastocysts were placed on a slide, air-dried, and fixed in absolute ethanol for $24 \mathrm{~h}$. Nuclei were counted under an epifluorescence microscope by staining with Hoechst $33342\left(10 \mu \mathrm{g} \mathrm{ml}^{-1}\right.$ in $2.3 \%(\mathrm{w} / \mathrm{v})$ sodium citrate).

\section{Experimental design}

Experiment 1 was designed to evaluate the effects of the three sperm treatments (unwashed, PBS washed and Percoll) on the acrosome reaction pattern. Subsamples containing 200 spermatozoa were examined $(\times 1000)$ at $0,30,60,90,120$ and $150 \mathrm{~min}$ of incubation and classified as described by Coy et al. (2002). This experiment was performed four times.

The aim of Expt 2 was to establish the optimal oocyte-sperm co-incubation time for each treatment. Four replicate experiments were performed, in which three periods of co-incubation $(2,4$ and $6 \mathrm{~h}$ ) were tested for each method of sperm preparation $(3 \times 3$ trial). After the co-incubation period, the oocytes were washed by gentle aspiration with a pipette to remove excess spermatozoa attached to the zona pellucida and cultured in fresh TALP medium for $16 \mathrm{~h}$.

The aim of Expt 3 was to determine whether the treatment could affect embryo development. Matured oocytes were co-incubated with spermatozoa for $2 \mathrm{~h}$ (DPBS-BSA-washed group), $6 \mathrm{~h}$ (unwashed group) and $2 \mathrm{~h}$ (Percoll-treated group), respectively, and then placed in NCSU-23 medium for further culture (144 h). These coincubation times were those at which highest outputs had been recorded in Expt 2. The experiment was performed five times.

Experiment 4 served to assess timing of oocyte activation and pronucleus formation for each treatment. Oocytes were removed from the culture dishes 4,6 and $8 \mathrm{~h}$ after insemination and washed and fixed as described above. The nuclear status of the oocytes 
was recorded as metaphase II, anaphase-telophase II or female pronucleus. The status of each spermatozoon was registered as unswollen, swollen or male pronucleus. This experiment was performed in triplicate.

\section{Statistical analysis}

Data are presented as mean \pm SEM and were fitted to the binomial variable model. In Expt 1, the number of live and dead spermatozoa and proportion of acrosome-reacted spermatozoa were analysed by twoway ANOVA. Sperm treatment and incubation time were considered as the main variables. The rate of oocyte penetration, number of sperm cells per penetrated oocyte (Expts 2 and 4), male pronucleus formation, monospermy and performance (Expt 2), and female and male nuclear status (Expt 4) were analysed by two-way ANOVA, considering sperm treatment and co-incubation time as the main variables. Performance was defined as the rate of monospermic oocytes with two pronuclei arising from the total number of inseminated oocytes. Cleavage, blastocyst formation rates and number of cells per blastocyst (Expt 3) were compared by one-way ANOVA. When ANOVA revealed a significant effect, the Tukey test was used to compare these data. The level of significance was set at $P<0.05$.

\section{Results}

\section{Acrosome reaction pattern}

The number of live non-reacted and reacted spermatozoa was found to depend on the sperm treatment $(P<0.001$, Fig. 1$)$. This value was highest for the unwashed treatment, compared with the groups washed with DPBS-BSA and treated with Percoll. The group treated with Percoll showed the highest number of reacted spermatozoa.

The number of live non-reacted spermatozoa steadily decreased over time in each of the treatment groups $(P<0.001)$. The numbers of reacted live spermatozoa showed a similar increase during the first $30 \mathrm{~min}$ for all three methods (Fig. 1b). After this period, the number of reacted, live spermatozoa in the unwashed and DPBSBSA-washed treatment groups decreased until $150 \mathrm{~min}$, whereas the numbers after the treatment with Percoll increased.

\section{In vitro fertilization}

The capacitation method affected all the variables evaluated $(P<0.001$, Table 1$)$ except the rate of male pronucleus formation, which was always $>95 \%$. Penetration rates and the number of spermatozoa per oocyte were highest after the treatment with Percoll. As expected, the lower the penetration rate, the higher the monospermy rate recorded. Final performance estimated as the rate of penetrated, monospermic oocytes with
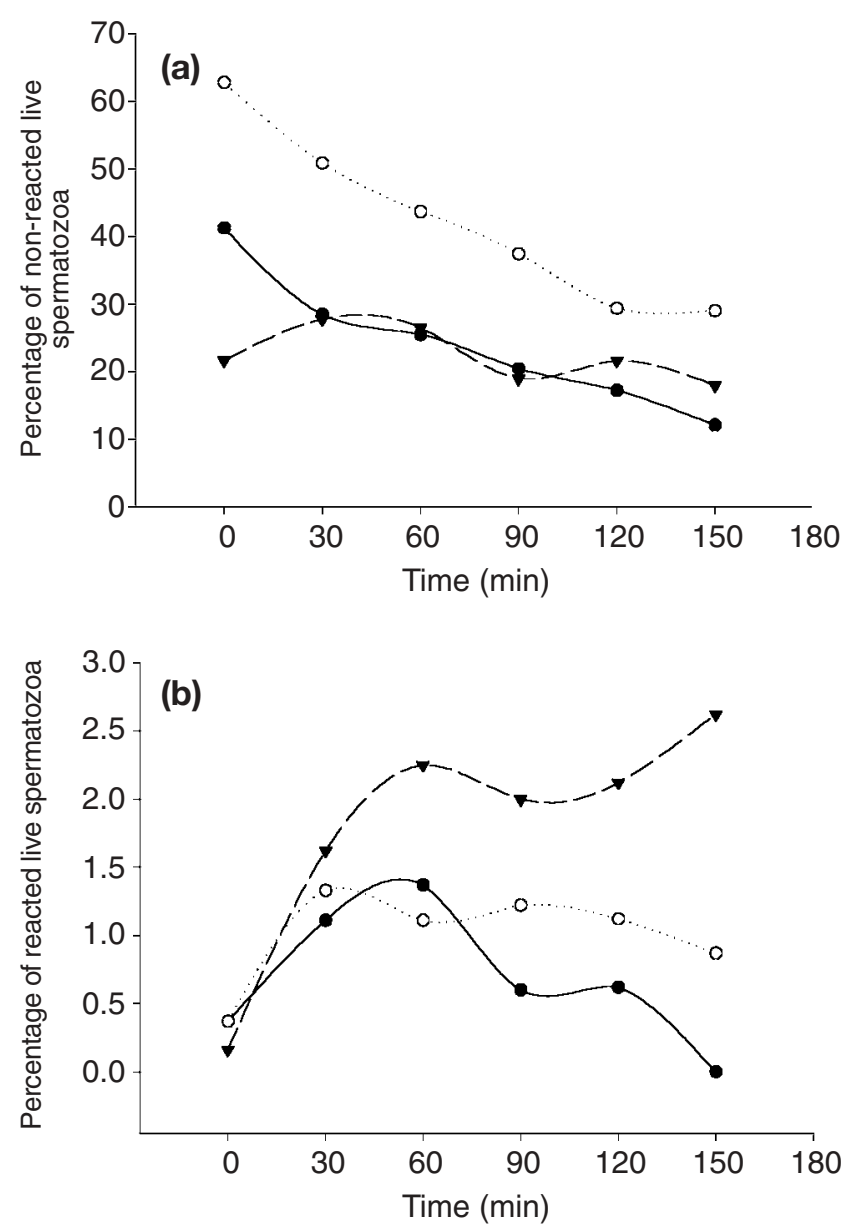

Fig. 1. Patterns of acrosome reaction in boar spermatozoa assessed by staining with fluorescein isothiocyanate-labelled peanut agglutinin and propidium iodide during incubation in Tyrode's albumin lactate pyruvate medium 0-150 min after three different sperm treatments: washing in Dulbecco's PBS supplemented with BSA $(\bullet)$; no washing $(\bigcirc)$; washing on a Percoll gradient $(\boldsymbol{\nabla})$. (a) Percentage of non-reacted live spermatozoa. (b) Percentage of reacted live spermatozoa.

respect to the total number of oocytes was highest in the DPBS-BSA-washed group.

Co-incubation time was found to affect the penetration rate, number of spermatozoa per oocyte and monospermy rate $(P<0.001)$. Both penetration and number of spermatozoa per oocyte increased over time. However, monospermy rates were higher at 2 and $4 \mathrm{~h}$ than after $6 \mathrm{~h}$ of incubation $(P<0.001)$.

The conditions yielding the highest rates of putative embryos were $2 \mathrm{~h}$ of co-incubation for spermatozoa treated with Percoll or washed in DPBS-BSA, and $6 \mathrm{~h}$ for unwashed spermatozoa.

\section{Embryo development}

At these selected co-incubation times $(2 \mathrm{~h}$ for spermatozoa washed with PBS or treated with Percoll 
Table 1. Effect of capacitation treatment of boar spermatozoa and co-incubation time on the IVF variables: penetration rate, mean number of spermatozoa per oocyte $(S / O)$, monospermy rate and rate of male pronucleus formation

\begin{tabular}{|c|c|c|c|c|c|c|c|}
\hline Treatment & Time $(\mathrm{h})$ & $\begin{array}{c}\text { Number of } \\
\text { oocytes }\end{array}$ & $\begin{array}{l}\text { Penetration } \\
\text { rate }(\%)\end{array}$ & $S / O$ & $\begin{array}{c}\text { Monospermy rate } \\
(\%)^{*}\end{array}$ & $\begin{array}{c}\text { Rate of male } \\
\text { pronucleus } \\
\text { formation }(\%)^{*}\end{array}$ & Performance $^{\dagger}$ \\
\hline \multirow[t]{3}{*}{ Washed with DPBS-BSA } & 2 & 114 & $55.3 \pm 4.7^{\mathrm{a}}$ & $1.7 \pm 0.1^{\mathrm{a}}$ & $63.5 \pm 6.1^{\mathrm{ab}}$ & 100 & $35.1 \pm 4.5^{\mathrm{a}}$ \\
\hline & 4 & 116 & $61.2 \pm 4.5^{\mathrm{a}}$ & $1.8 \pm 0.1^{\mathrm{a}}$ & $54.9 \pm 6.0^{\mathrm{ab}}$ & 100 & $33.6 \pm 4.4^{\mathrm{a}}$ \\
\hline & 6 & 106 & $62.3 \pm 4.7^{\mathrm{a}}$ & $2.1 \pm 0.2^{\mathrm{a}}$ & $53.0 \pm 6.2^{\mathrm{ab}}$ & 100 & $33.0 \pm 4.6^{\mathrm{a}}$ \\
\hline \multirow[t]{3}{*}{ Not washed } & 2 & 113 & $16.8 \pm 3.5^{b}$ & $1.4 \pm 0.2^{\mathrm{a}}$ & $79.0 \pm 9.6^{b}$ & 100 & $13.3 \pm 3.2^{b c}$ \\
\hline & 4 & 103 & $45.6 \pm 4.9^{a}$ & $1.5 \pm 0.1^{\mathrm{a}}$ & $70.2 \pm 6.7^{b}$ & 100 & $32.0 \pm 4.6^{\mathrm{a}}$ \\
\hline & 6 & 108 & $50.0 \pm 4.8^{\mathrm{a}}$ & $1.7 \pm 0.1^{\mathrm{a}}$ & $51.9 \pm 6.9^{\mathrm{ab}}$ & $96.3 \pm 2.6$ & $25.0 \pm 4.2^{\mathrm{abc}}$ \\
\hline \multirow[t]{3}{*}{ Percoll } & 2 & 113 & $61.0 \pm 4.6^{\mathrm{a}}$ & $2.7 \pm 0.2^{\mathrm{ab}}$ & $42.0 \pm 6.0^{\mathrm{ac}}$ & 100 & $25.7 \pm 4.1^{\mathrm{ab}}$ \\
\hline & 4 & 131 & $90.8 \pm 2.5^{c}$ & $4.1 \pm 0.3^{b}$ & $22.7 \pm 3.9^{\mathrm{cd}}$ & 100 & $20.6 \pm 3.6^{\mathrm{abc}}$ \\
\hline & 6 & 80 & $96.2 \pm 2.1^{\mathrm{c}}$ & $9.9 \pm 0.8^{c}$ & $6.5 \pm 2.8^{\mathrm{d}}$ & 100 & $6.3 \pm 2.7^{\mathrm{c}}$ \\
\hline Treatment & & & $<0.001$ & $<0.001$ & $<0.001$ & 0.162 & $<0.001$ \\
\hline Time & & & $<0.001$ & $<0.001$ & $<0.001$ & 0.066 & 0.096 \\
\hline Treatment $\times$ time & & & 0.003 & $<0.001$ & 0.197 & 0.055 & 0.002 \\
\hline
\end{tabular}

*From the penetrated oocytes.

$\dagger$ Performance was defined as the rate of monospermic oocytes with two pronuclei expressed as a proportion of the total number of inseminated oocytes.

${ }^{a-d}$ Different superscripts in the same column indicate significantly different values $(P<0.05)$.

DPBS-BSA: Dulbecco's phosphate-buffered saline supplemented with $0.1 \%$ BSA.

Table 2. Effect of capacitation treatment of boar spermatozoa on early embryo development variables according to coincubation time

\begin{tabular}{|c|c|c|c|c|c|}
\hline Treatment & Time (h) & $\begin{array}{l}\text { Number of } \\
\text { embryos }\end{array}$ & Cleavage (\%) & Blastocyst (\%) & $\begin{array}{c}\text { Number of cells in } \\
\text { blastocyst }\end{array}$ \\
\hline Washed with DPBS-BSA & 2 & 429 & $26.6 \pm 2.1^{\mathrm{a}}$ & $10.5 \pm 2.9^{\mathrm{a}}$ & $15.8 \pm 2.4$ \\
\hline Not washed & 6 & 403 & $50.1 \pm 2.5^{b}$ & $9.4 \pm 2.1^{\mathrm{a}}$ & $24.1 \pm 3.9$ \\
\hline Percoll & 2 & 418 & $43.5 \pm 2.4^{b}$ & $18.1 \pm 2.9^{b}$ & $19.0 \pm 1.9$ \\
\hline Treatment & & & $<0.001$ & 0.027 & 0.221 \\
\hline
\end{tabular}

${ }^{a, b}$ Different superscripts in the same column indicate significantly different values $(P<0.05)$.

DPBS-BSA: Dulbecco's phosphate-buffered saline supplemented with $0.1 \%$ BSA.

and $6 \mathrm{~h}$ for unwashed spermatozoa), the method of sperm treatment significantly affected cleavage and blastocyst rates $(P<0.05$, Table 2$)$; but the number of cells per blastocyst did not differ significantly $(P=0.221)$. Unwashed and Percoll-treated spermatozoa achieved higher cleavage rates than spermatozoa washed with DPBS-BSA, whereas Percoll treatment produced the greatest number of blastocysts.

\section{Timing of male and female nuclear status}

Sperm treatment and co-incubation time also affected penetrability $(P<0.001$, Table 3$)$, with highest penetrability rates recorded for the group treated with Percoll; rates were lower at $4 \mathrm{~h}$ than at 6 or $8 \mathrm{~h}$.

The changes observed in the female nucleus from metaphase II to anaphase-telophase II and to pronucleus formation were time-dependent $(P<0.01)$. Only the percentage of female pronuclei was significantly affected by sperm treatment $(P<0.01)$. In the group treated with Percoll, the change to the female pronucleus observed at $6 \mathrm{~h}$ occurred in a higher proportion of the oocytes than in the other two groups (35.9 versus 12.2 and $7.1 \%$, respectively).

Data relating to male nuclear status indicated that the percentage of spermatozoa with an unswollen head, swollen head and pronucleus was significantly affected by time $(P<0.001$, Table 3$)$, but only the unswollen and pronucleus stages were affected by sperm treatment $(P<0.05)$. The lack of a treatment effect on the number of spermatozoa with swollen heads may be due to interaction between time and sperm treatment $(P<0.001)$. Once again, Percoll-treatment was related to faster male pronucleus formation than no washing, and this effect was similar to that of DPBS-BSA-treatment, as shown at $6 \mathrm{~h}(33.3,7.1$ and $12.2 \%$, respectively). 
Table 3. Effect of capacitation treatment of boar spermatozoa on the timing of male and female nuclear status, penetration rate and mean number of spermatozoa $(S)$ per oocyte $(O)$

\begin{tabular}{|c|c|c|c|c|c|c|c|c|c|c|}
\hline \multirow[b]{2}{*}{ Treatment } & \multirow[b]{2}{*}{ Time $(\mathrm{h})$} & \multirow[b]{2}{*}{$\begin{array}{l}\text { Number } \\
\text { of oocytes }\end{array}$} & \multirow[b]{2}{*}{$\begin{array}{c}\text { Penetration rate } \\
(\%)\end{array}$} & \multirow[b]{2}{*}{$S / O$} & \multicolumn{3}{|c|}{ Female nuclear status } & \multicolumn{3}{|c|}{ Male nuclear status } \\
\hline & & & & & $\begin{array}{l}\text { Met II } \\
(\%)\end{array}$ & $\begin{array}{c}\text { Ana-Telo II } \\
(\%)\end{array}$ & $\begin{array}{c}\text { Pronucleus } \\
(\%)\end{array}$ & $\begin{array}{l}\text { Unswollen } \\
(\%)\end{array}$ & $\begin{array}{c}\text { Swollen } \\
(\%)\end{array}$ & $\begin{array}{c}\text { Pronucleus } \\
(\%)\end{array}$ \\
\hline \multirow{3}{*}{$\begin{array}{l}\text { Washed with } \\
\text { DPBS-BSA }\end{array}$} & 4 & 74 & $20.3 \pm 4.7$ & $1.3 \pm 0.2$ & $33.3 \pm 12.6^{\mathrm{a}}$ & $66.7 \pm 12.6^{\mathrm{ab}}$ & $0^{\mathrm{a}}$ & $73.3 \pm 11.8^{\mathrm{a}}$ & $26.7 \pm 11.8^{\mathrm{ab}}$ & $0^{\mathrm{a}}$ \\
\hline & 6 & 73 & $67.1 \pm 5.6$ & $2.5 \pm 0.2$ & $8.2 \pm 4.0^{\mathrm{ab}}$ & $79.6 \pm 5.8^{\mathrm{ab}}$ & $12.2 \pm 4.7^{\mathrm{a}}$ & $18.4 \pm 5.6^{\mathrm{bc}}$ & $69.4 \pm 6.7^{c}$ & $12.2 \pm 4.7^{\mathrm{ab}}$ \\
\hline & 8 & 66 & $70.0 \pm 6.0$ & $2.4 \pm 0.2$ & $4.4 \pm 3.0^{b}$ & $15.2 \pm 5.4^{\mathrm{c}}$ & $80.4 \pm 5.9^{b}$ & $6.5 \pm 3.7^{b}$ & $10.9 \pm 4.6^{\mathrm{a}}$ & $82.6 \pm 5.7^{c}$ \\
\hline \multirow[t]{3}{*}{ Not washed } & 4 & 68 & $22.1 \pm 5.1$ & $1.3 \pm 0.2$ & $20.0 \pm 10.7^{a b}$ & $80.0 \pm 10.7^{\mathrm{ab}}$ & $0^{\mathrm{a}}$ & $80.0 \pm 10.7^{a}$ & $20.0 \pm 10.7^{\mathrm{ab}}$ & $0^{\mathrm{a}}$ \\
\hline & 6 & 72 & $77.8 \pm 4.9$ & $1.9 \pm 0.2$ & $17.9 \pm 5.2^{\mathrm{ab}}$ & $75.0 \pm 5.8^{\mathrm{ab}}$ & $7.1 \pm 3.5^{\mathrm{a}}$ & $44.6 \pm 6.7^{\mathrm{ac}}$ & $48.2 \pm 6.7^{\mathrm{bc}}$ & $7.1 \pm 3.5^{\mathrm{a}}$ \\
\hline & 8 & 58 & $84.5 \pm 5.0$ & $2.9 \pm 0.2$ & $6.1 \pm 3.5^{\mathrm{ab}}$ & $12.2 \pm 4.7^{\mathrm{c}}$ & $81.6 \pm 5.6^{b}$ & $6.1 \pm 3.5^{b}$ & $20.4 \pm 5.8^{\mathrm{a}}$ & $73.5 \pm 6.4^{\mathrm{c}}$ \\
\hline \multirow[t]{3}{*}{ Percoll } & 4 & 60 & $71.7 \pm 6.0$ & $2.2 \pm 0.2$ & $9.3 \pm 4.5^{\mathrm{ab}}$ & $90.7 \pm 4.5^{\mathrm{a}}$ & $0^{\mathrm{a}}$ & $51.2 \pm 7.7^{\mathrm{ac}}$ & $48.8 \pm 7.7^{\mathrm{bc}}$ & $0^{\mathrm{a}}$ \\
\hline & 6 & 47 & $83.0 \pm 5.5$ & $3.2 \pm 0.4$ & $7.7 \pm 4.3^{\mathrm{ab}}$ & $56.4 \pm 8.0^{b}$ & $35.9 \pm 7.8^{c}$ & $33.3 \pm 7.7^{c}$ & $33.3 \pm 7.7^{\mathrm{ab}}$ & $33.3 \pm 7.7^{b}$ \\
\hline & 8 & 36 & $97.2 \pm 2.8$ & $5.9 \pm 0.8$ & $5.7 \pm 3.4^{\mathrm{ab}}$ & $0^{\mathrm{c}}$ & $94.3 \pm 4.0^{\mathrm{b}}$ & $2.9 \pm 2.9^{b}$ & $8.6 \pm 4.8^{\mathrm{a}}$ & $88.6 \pm 5.5^{c}$ \\
\hline Treatment & & & $<0.001$ & $<0.001$ & 0.126 & 0.428 & 0.003 & 0.033 & 0.603 & 0.012 \\
\hline Time & & & $<0.001$ & $<0.001$ & 0.005 & $<0.001$ & $<0.001$ & $<0.001$ & $<0.001$ & $<0.001$ \\
\hline Treatment $\times$ time & & & $<0.001$ & $<0.001$ & 0.126 & 0.012 & 0.092 & 0.025 & $<0.001$ & 0.187 \\
\hline
\end{tabular}

${ }^{a-c}$ Different superscripts in the same column indicate significantly different values $(P<0.05)$.

DPBS-BSA: Dulbecco's phosphate-buffered saline supplemented with 0.1\% BSA; Met II: metaphase II; Ana-Tel II: anaphase-telophase II. 
The synchronized development of female and male nuclei observed at any time for each treatment (Table 3) is worthy of note. Pronuclear developmental rates were always in close agreement.

\section{Discussion}

The selection of spermatozoa in vitro in an artificial medium by different procedures is unlikely to correspond to events occurring in vivo in which co-ordinated modification followed by the removal of male macromolecules from the sperm surface leads to remodelling of the plasma membrane (Hunter and Rodriguez-Martinez, 2002). This stepwise modification of viable spermatozoa results in the arrival of a small number of competent spermatozoa at the site of fertilization close to the time of ovulation. This physiological pattern guarantees the prolonged presence of live spermatozoa near the oocyte ready to undergo the acrosome reaction and thus increases the possibility of successful penetration (Hunter, 1997; Hunter and Rodriguez-Martinez, 2002).

Sperm capacitation in vitro may enable sperm penetration of the zona pellucida and fusion with the vitelline membrane, but does not always promote the formation of a viable zygote (Hunter and RodriguezMartinez, 2002). Both freshly ejaculated and frozenthawed boar semen have been used successfully for in vitro fertilization. However, reported rates of fertilization show a wide variation that may be attributed to differences in sperm capacitation (Niemann and Rath, 2001).

The Percoll procedure yields pure fractions of spermatozoa, whereas the washing technique produces cell pellets that contain a heterogeneous population of spermatozoa along with amorphous material and seminal plasma (Grant et al., 1994). Moreover, spermatozoa washed on a Percoll gradient are partly capacitated (Berger et al., 1989). In the present study, three commonly used sperm treatments were tested and the results indicate that treatment with Percoll leads to the behaviour pattern that most closely resembles physiological behaviour, in that the number of reacted live spermatozoa steadily increases throughout incubation. As expected, higher penetration rates were observed after pretreatment with Percoll. Leaving spermatozoa unwashed or washing them with DPBSBSA gave rise to a heterogeneous sperm population. It is possible that capacitation and the acrosome reaction occur during co-incubation in the TALP medium, as the presence of calcium and bicarbonate in the medium enhances these processes (Harrison et al., 1993; Green and Watson, 2001). As a consequence, penetration occurred later during incubation in these groups.

Although it was expected that during coincubation, penetration rates would increase and monospermy rates would fall, the present results provide additional information concerning the capacitation system. It would seem that $2 \mathrm{~h}$ of contact was sufficient when the spermatozoa had been washed with DPBS-BSA or Percoll, as a longer incubation period leads only to an increased polyspermy rate. These findings are in disagreement with those reported by Martinez et al. (1996), who determined IVF variables using spermatozoa that were unwashed or washed with DPBS-BSA and observed no penetration during the first $2 \mathrm{~h}$ of co-culture. This difference may be explained by the use of immature oocytes and the fact that these authors fixed the oocytes after insemination. Thus, the spermatozoa attached to the vitelline membrane or to the zona pellucida could not be assessed as there was insufficient time for the oocyte membrane to be penetrated. Nevertheless, these investigators noted that increasing the co-culture time enhanced polyspermy. Moreover, the discrepancy between the present results and those described by Rho et al. (2001) using goat spermatozoa treated with Percoll could also be due to earlier oocyte fixation in the previous study or a species difference. Knowledge of the optimal co-incubation time for each capacitation system will serve to improve performance rates in future experiments.

Larsson and Rodriguez-Martinez (2000) reported that the cleavage rate was more suitable than the blastocyst rate for evaluating semen samples, probably because the blastocyst is much more dependent than cleavage on culture conditions during embryo development. Nevertheless, it is the opinion of the present authors that blastocyst rate is the consequence of a good cleavage rate and that assessment of the rate of cleavage is therefore a less objective measure of embryo development than assessment of blastocyst rate (Coy et al., 2002). Similar cleavage rates were recorded in the unwashed and Percoll-treated groups, whereas the unwashed and DPBS-BSA groups showed similar blastocyst rates. According to the criteria of Coy et al. (2002), the treatment that the unwashed group received would be classified as an effective capacitation system similar to that using Percoll. When blastocyst formation was taken as the end-point for evaluating sperm pretreatment, treatment with Percoll provided the best results. The explanation for this finding could be that a short exposure of oocytes to spermatozoa improves IVF results (Dirnfeld et al., 1999), as long-term exposure of oocytes to a large number of spermatozoa would create suboptimal conditions as a result of the generation of excessive reactive oxygen species (ROS) (Quinn et al., 1998), which have a detrimental effect on cells. Jaakma et al. (1997) proposed that embryonic development up to the formation of the blastocyst varies depending on the procedures used for sperm preparation and fertilization. Hence, the improved rate of blastocyst development after centrifugation of sperm on a Percoll gradient appears to confirm the findings of Grant et al. (1994), Jeon and Yang (2001) and Rho et al. (2001). 
The rationale described above is also consistent with the findings of the present study, in which the capacitation system influenced the time of male and female pronucleus formation, and oocytes fertilized by spermatozoa treated with Percoll reached the pronuclear stage quicker than oocytes fertilized by unwashed spermatozoa. Under the experimental conditions described in the present study, $6 \mathrm{~h}$ of coincubation was the critical time for comparing the three sperm treatments. After $4 \mathrm{~h}$ of incubation, both the female and male nuclei were still at metaphase II and unswollen head stages, respectively, and by $8 \mathrm{~h}$ the nuclei had reached the female and male pronuclear stage. These results differ from observations made by Laurincik et al. (1994), probably as a result of the IVF system used, or the insufficient maturation of oocytes, as Laurincik et al. (1994) detected a large difference between oocytes matured in vivo and in vitro. In the present study, a faster and higher rate of male pronucleus formation (at $6 \mathrm{~h}$ of co-culture) was recorded in Percoll-treated groups than the values quoted by Laurincik et al. (1994). Therefore, it is clear that, besides oocyte quality, it is essential to consider sperm treatment before IVF to get optimal results.

According to Van den Zwalmen et al. (1991), centrifugation in Percoll is more than simple washing of spermatozoa, and has been shown to raise the probability of fertilization in IVF attempts. In a study by de Maistre et al. (1996), examination of spermatozoa after centrifugation with Percoll gradient revealed that areas actively involved in the processes of capacitation and acrosomal reaction were frequently labelled by lectins, indicating that this method modifies the glycosylation pattern of structures important for egg fertilization. Centrifugation with Percoll gradient may either trigger the early steps of the acrosomal reaction, which would increase the expression of sugar moieties on the sperm surface, or select a subpopulation of highly glycosylated spermatozoa.

Zygotes cleaved early are more competent in terms of development up to the blastocyst stage than those cleaved later (Ward et al., 2001). In addition, it is possible that delayed penetration resulting in the fertilization of an aged oocyte impairs development. It is the opinion of the present authors that, compared with other pretreatments of spermatozoa, the treatment using Percoll is the most appropriate under the conditions used at present for the production of embryos in vitro.

The concurrent development of both male and female nuclei in the three treatment groups examined is of particular interest, as the proportions of oocytes and spermatozoa reaching this nuclear status were similar at each stage of incubation. This finding confirms that this capacitation system and oocyte maturation system are able to produce zygotes in vitro that are able to develop to the early embryo stage, although there are still many other factors affecting development that need to be improved (for example, embryo culture medium and amount of polyspermy).

It may be concluded that, despite the efficiency of the three sperm treatments tested in yielding bastocysts, the performance of this system of production of pig embryos in vitro was improved after preselecting spermatozoa by centrifugation on a Percoll gradient.

This research was supported by the project AGL 2000-0485C02-01. The authors thank E. Garcia and E. Sellés for technical assistance.

\section{References}

Abeydeera LR (2002) In vitro production of embryos in swine Theriogenology $\mathbf{5 7}$ 256-273

Abeydeera LR, Wang WH, Cantley TC, Rieke A, Prather RS and Day BN (1998a) Presence of epidermal growth factor during in vitro maturation of pig oocytes and embryo culture can modulate blastocyst development after in vitro fertilization Molecular Reproduction and Development $\mathbf{5 1}$ 395-401

Abeydeera LR, Wang WH, Cantley TC, Prather RS and Day BN (1998b) Presence of beta-mercaptoethanol can increase the glutathione content of pig oocytes matured in vitro and the rate of blastocyst development after in vitro fertilization Theriogenology $\mathbf{5 0}$ 747-756

Berger T, Marrs RP and Moyer DL (1985) Comparison of techniques for selection of motile spermatozoa Fertility and Sterility 43 268-373

Berger T, Davis A, Wardrip NJ and Hedrick JL (1989) Sperm binding to the pig zona pellucida and inhibition of binding by solubilized components of the zona pellucida Journal of Reproduction and Fertility 86 559-565

Coy P, Gadea J, Romar R, Matás C and García E (2002) Effect of in vitro fertilization medium on the acrosome reaction, cortical reaction, zona pellucida hardening, and in vitro development in the pig Reproduction 124 279-288

Daya S, Gwatkin RBL and Bissessar H (1987) Separation of motile human spermatozoa by means of glass bead column Gamete Research 17 375-380

de Maistre E, Béné MC, Foliguet B, Touati F and Faure GC (1996) Centrifugation on Percoll gradient enhances fluorescent lectin binding on human sperm: a flow cytometric analysis Archives of Andrology 37 179-187

Dirnfeld M, Bider D, Koifman M, Calderon I and Abramovici H (1999) Shortened exposure of oocytes to spermatozoa improves in vitro fertilization outcome: a prospective, randomized, controlled study Human Reproduction 14 2562-2564

Funahashi H and Day BN (1993) Effects of the duration of exposure to supplemental hormones on cytoplasmic maturation of pig oocytes in vitro. Journal of Reproduction and Fertility 98 179-185

Funahashi H and Day BN (1997) Advances in in vitro production of porcine embryos Journal of Reproduction and Fertility 52 271-283

Funahashi H and Nagai T (2001) Regulation of in vitro penetration of frozen-thawed boar spermatozoa by caffeine and adenosine Molecular Reproduction and Development 58 424-431

Funahashi H, Cantley TC and Day BN (1997) Synchronization of meiosis in porcine oocytes by exposure to dibutyryl cyclic adenosine monophosphate improves developmental competence following in vitro fertilization Biology of Reproduction 57 49-53

Gadea J and Matás C (2000) Sperm factors related to in vitro penetration of porcine oocytes Theriogenology 54 1343-1357

Grant SA, Long SE and Parkinson TJ (1994) Fertilizability and structural properties of boar spermatozoa prepared by Percoll gradient centrifugation Journal of Reproduction and Fertility $\mathbf{1 0 0}$ $477-483$

Green CE and Watson PF (2001) Comparison of the capacitation-like state of cooled boar spermatozoa with true capacitation Reproduction 122 889-898 
Han YM, Wang WH, Abeydeera LR, Peterson AL, Kim JH, Murphy C, Day BN and Prather RS (1999) Pronuclear localization before the first cell division determines ploidy of polyspermic pig embryos Biology of Reproduction 61 1340-1346

Harrison RAP (1997) Sperm plasma membrane characteristics and boar semen fertility Journal of Reproduction and Fertility 52 195-211

Harrison RAP, Mairet B and Miller NGA (1993) Flow cytometric studies of bicarbonate-mediated $\mathrm{Ca}^{2+}$ influx in boar sperm populations Molecular Reproduction and Development 35 197-208

Hunter RHF (1997) Sperm dynamics in the female genital tract: interactions with Fallopian tube microenvironments. In Microscopy of Reproduction and Development: A Dynamic Approach pp 35-45 Ed. PM Motta. Antonio Delfino Editore, Rome

Hunter RHF and Rodriguez-Martínez H (2002) Analysing mammalian fertilization: reservation and potential pitfalls with an in vitro approach Zygote 10 11-15

Iwasaki T, Kimura E and Totsukawa K (1999) Studies on a chemically defined medium for in vitro culture of in vitro matured and fertilized porcine oocytes Theriogenology 51 709-720

Jaakma Ü, Zhang BR, Larsson B, Niwa K and Rodriguez-Martinez H (1997) Effects of sperm treatments on the in vitro development of bovine oocytes in semidefined and defined media Theriogenology $\mathbf{4 8}$ 711-720

Jeong BS and Yang X (2001) Cysteine, glutathione, and Percoll treatments improve porcine oocyte maturation and fertilization in vitro. Molecular Reproduction and Development 59 330-335

Kikuchi K, Onishi A, Kashiwazaki N, Iwamoto M, Noguchi J, Kaneko H, Akita T and Nagai T (2002) Successful piglet production after transfer of blastocysts produced by a modified in vitro system Biology of Reproduction 66 1033-1041

Larsson B and Rodriguez-Martinez H (2000) Can we use in vitro fertilization tests to predict semen fertility? Animal Reproduction Science 60-61 327-336

Laurincik J, Rath D and Niemann H (1994) Differences in pronucleus formation and first cleavage following in vitro fertilization between pig oocytes matured in vivo and in vitro. Journal of Reproduction and Fertility 102 277-284

Lonergan P, Khatir H, Piumi F, Rieger D, Humblot $\mathbf{P}$ and Boland MP (1999) Effect of time interval from insemination to first cleavage on the developmental characteristics, sex ratio and pregnancy rate after transfer of bovine embryos Journal of Reproduction and Fertility 117 159-167

Long CR, Dobrinsky JR and Johnson LA (1999) In vitro production of pig embryos: comparisons of culture media and boars Theriogenology $\mathbf{5 1}$ 1375-1390

Macháty Z, Day BN and Prather RS (1998) Development of early porcine embryos in vitro and in vivo. Biology of Reproduction 59 451-455

Mann T (1964) The Biochemistry of Semen and the Male Reproductive Tract Methuen, London

Martinez E, Vazquez JM, Matás C, Gadea J, Alonso MI and Roca J (1996) Oocyte penetration by fresh or stored diluted boar spermatozoa before and after in vitro capacitation treatments Biology of Reproduction 55 134-140

Matás C, Martinez E, Vázquez JM, Roca J and Gadea J (1996) In vitro penetration assay of boar sperm fertility: effect of various factors on the penetrability of immature pig oocytes Theriogenology 46 503-596

Matás C, Romar R, Coy P, Campos I, Gadea J, Sellés E and Ruiz S (2000) Effect of $\mathrm{Ca}^{2+}$ in IVF medium on penetration of boar spermatozoa into pig oocytes matured in vitro. Theriogenology $\mathbf{5 3} 425$ (Abstract)

Nagai T (1994) Current status and perspectives in IVM-IVF of porcine oocytes Theriogenology 41 73-78

Niemann H and Rath D (2001) Progress in reproductive biotechnology in swine Theriogenology 56 1291-1304

Parrish JJ and Foote RH (1987) Quantification of bovine sperm separation by swim-up method. Relationship to sperm motility, integrity of acrosomes, sperm migration in polyacrylamide gel and fertility Journal of Andrology 8 259-266

Parrish JJ, Krogenaes A and Susko-Parrish JL (1995) Effect of bovine sperm separation by either swim-up or Percoll method on success of in vitro fertilization and early embryonic development Theriogenology 44 859-869

Pereira RJ, Tuli RK, Wallenhorst S and Holtz W (2000) The effect of heparin, caffeine and calcium ionophore A23187 on in vitro induction of the acrosome reaction in frozen-thawed bovine and caprine spermatozoa Theriogenology 54 185-192

Petters RM and Wells KD (1993) Culture of pig embryos Journal of Reproduction and Fertility Supplement 48 61-73

Quinn P, Lydic ML, Ho M, Bastuba M, Hendee F and Brody F (1998) Confirmation of the beneficial effects of brief co-incubation of gametes in human in vitro fertilization Fertility and Sterility 69 339-402

Rath D, Long CR, Dobrinsky JR, Welch GR, Schreier LL, and Johnson LA (1999) In vitro production of sexed embryos for gender preselection: high-speed sorting of X-chromosome bearing sperm to produce pigs after embryo transfer Journal of Animal Science 773346 3352

Rho Gj, Hahnel AC and Betteridge KJ (2001) Comparisons of oocyte maturation times and of three methods of sperm preparation for their effects on the production of goat embryos in vitro. Theriogenology 56 503-516

Steeno O, Adimoelja A and Steeno J (1985) Separation of X and Y bearing human spermatozoa with the Sephadex gel filtration method Andrology 7 95-97

Sun QY, Lai L, Bonk A, Prather RS and Schatten H (2001) Cytoplasmic changes in relation to nuclear maturation and early embryo developmental potential of porcine oocytes: effects of gonadotropins, cumulus cells, follicular size, and protein synthesis inhibition Molecular Reproduction and Development 59 192-198

Van den Zwalmen P, Bertin-Segal G, Geerts L, Debauche C and Schoysman R (1991) Sperm morphology and IVF pregnancy rate: comparison between Percoll gradient centrifugation and swim-up procedures Human Reproduction 6 581-588

Ward F, Rizos D, Corridan D, Quinn K, Boland $M$ and Lonergan P (2001) Paternal Influence on the time of first embryonic cleavage post insemination and the implications for subsequent bovine embryo development in vitro and fertility in vivo. Molecular Reproduction and Development 60 47-55

Yanagimachi R (1994) Mammalian fertilization. In The Physiology of Reproduction pp 189-317 Eds E Knobil and JD Neill. Raven Press, New York.

Received 12 June 2002.

First decision 8 August 2002.

Revised manuscript received 16 September 2002.

Accepted 16 September 2002. 